\title{
Advancing careers in medical education: 'Practice architectures' for success in a resource-constrained setting
}

Citation for published version (APA):

Olupeliyawa, A. M., Hu, W. C. Y., \& Stalmeijer, R. E. (2021). Advancing careers in medical education: 'Practice architectures' for success in a resource-constrained setting. Medical Teacher, 43(8), 884-888. https://doi.org/10.1080/0142159X.2021.1931082

Document status and date:

Published: 03/08/2021

DOI:

10.1080/0142159X.2021.1931082

Document Version:

Publisher's PDF, also known as Version of record

Document license:

Taverne

Please check the document version of this publication:

- A submitted manuscript is the version of the article upon submission and before peer-review. There can be important differences between the submitted version and the official published version of record.

People interested in the research are advised to contact the author for the final version of the publication, or visit the DOI to the publisher's website.

- The final author version and the galley proof are versions of the publication after peer review.

- The final published version features the final layout of the paper including the volume, issue and page numbers.

Link to publication

\footnotetext{
General rights rights.

- You may freely distribute the URL identifying the publication in the public portal. please follow below link for the End User Agreement:

www.umlib.nl/taverne-license

Take down policy

If you believe that this document breaches copyright please contact us at:

repository@maastrichtuniversity.nl

providing details and we will investigate your claim.
}

Copyright and moral rights for the publications made accessible in the public portal are retained by the authors and/or other copyright owners and it is a condition of accessing publications that users recognise and abide by the legal requirements associated with these

- Users may download and print one copy of any publication from the public portal for the purpose of private study or research.

- You may not further distribute the material or use it for any profit-making activity or commercial gain

If the publication is distributed under the terms of Article 25fa of the Dutch Copyright Act, indicated by the "Taverne" license above, 


\title{
Advancing careers in medical education: 'Practice architectures' for success in a resource-constrained setting
}

\author{
Asela M. Olupeliyawa ${ }^{\mathrm{a}} \mathbb{D}$, Wendy C. Y. Hu ${ }^{\mathrm{b}}$ (D) and Renée E. Stalmeijer ${ }^{\mathrm{c}}$ (D) \\ ${ }^{a}$ Department of Medical Education, Faculty of Medicine, University of Colombo, Colombo, Sri Lanka; ${ }^{b}$ School of Medicine, Western \\ Sydney University, Campbelltown, Australia; 'Department of Educational Development and Research, School of Health Professions \\ Education, Faculty of Health, Medicine, and Life Sciences, Maastricht University, Maastricht, The Netherlands
}

\begin{abstract}
Introduction: Advancement of careers in medical education remains a challenge around the world and is under-researched in resource-constrained contexts. Using the Theory of Practice Architectures (TPA) as a conceptual lens, we investigated the emergence and subsequent development of medical education careers in a resource-constrained country.

Methods: Qualitative semi-structured interviews were conducted with a purposive sample of 14 early-career and leading medical educators from all 9 medical schools and the 1 postgraduate institute in Sri Lanka. Thematic analysis was performed, informed by the three conceptual lenses of TPA: discursive-cultural, material-economic, and socio-political.

Results: Three themes were identified: faculty development as a career-building discourse (discursive-cultural); leadership focused on creating a workforce with expertise in medical education, equal to clinical medicine specialties (material-economic); and collaborative professional networks in health professions education originating from faculty development activities (socio-political).

Conclusion: Using TPA, our findings highlight that faculty development can foster a powerful discourse for promoting academic careers in medical education. Medical education leaders can also play a critical role by establishing formal training programmes in medical education, and collaborative professional networks can improve visibility of careers in medical education, particularly when participants share expertise and resources between institutions and health professions, across the continuum of undergraduate to postgraduate training. TPA can also be used to better understand how cultural, material-economic and socio-political factors can enhance or hinder career development in different contexts, whether resource-limited or well-resourced.
\end{abstract}

\section{KEYWORDS}

Staff development; international medical education; teacher training

\section{Introduction}

Worldwide, advancement in the field of medical education is gathering pace, with a growing international community of scholars in medical education. However, challenges to developing and sustaining careers in medical education (ME) continue. Lack of visibility, unplanned and serendipitous career entry and progression (Hu et al. 2015), as well as tensions in professional identity formation (Sethi et al. 2018), hinder the careers of medical educators.

Availability of resources is another influence on career development, particularly in resource-constrained (or 'lowand middle-income') settings. Educators in these settings often aspire to reform ME and to join the global community of scholars, aiming to build local ME capacity (Karunathilake et al. 2006; Kiguli-Malwadde et al. 2015). Previous research on ME careers in well-resourced settings has focused on the experiences of individuals ( $\mathrm{Hu}$ et al. 2015; Sethi et al. 2018) and on the indirect influences of institutional structures such as Medical Education Units on career opportunities and recognition (Varpio, O'Brein, Hu, et al. 2017). Research on the broader range of contextual influences on ME careers is sparse. Increased interest and

\section{Practice points}

- Faculty development activities can foster a discourse about the need for expertise in medical education and stimulate academic careers in medical education.

- Medical education leaders can facilitate careers in medical education by identifying early career medical educators, establishing formal postgraduate training programmes in medical education, and promoting faculty development activities, thus encouraging an expert workforce in medical education.

- Collaborative professional networks improve visibility of careers in medical education when they share expertise and resources across institutions and health professions, and across the continuum of medical education, from undergraduate to postgraduate programmes.

growth of ME in resource-constrained contexts warrants research that is transferrable to ME careers in all contexts. 
Sri Lanka is notable for its advancement of ME careers within a context of significant resource constraints. ME was recently recognised as a career of equal standing to clinical medicine specialties, formalised by a training pathway offered by the national postgraduate training institution for all medical specialties, the Postgraduate Institute of Medicine (Postgraduate Institute of Medicine (PGIM) Doctor of Medicine (MD) and Board Certification in Medical Education 2016). This recognition is unusual in any international context, including countries with a reputation for ME scholarship and research (Varpio, O'Brein, $\mathrm{Hu}$, et al. 2017). Examining how ME careers came to be established in Sri Lanka, and the contextual factors which stimulated career development, may uncover lessons relevant to other countries.

The Theory of Practice Architectures (TPA) is a framework for exploring how professional practices develop and are shaped by their situational context (Mahon et al. 2017). Mainly used in education research, an example is Kemmis et al.'s (2014) exploration of contextual influences on mentoring newly qualified teachers in a remote rural location. TPA examines and describes practices within particular contexts through three interconnected 'arrangements'. These arrangements explain how educators come to talk about, enact, and relate to certain practices (Mahon et al. 2017). They are the: (1) discursive-cultural (e.g. professional jargon, discourses), (2) material-economic (e.g. physical environment, formal job descriptions) and (3) socio-political (e.g. power differentials, relationships). Together, these arrangements form the spaces, structures and systems which professionals inhabit, the 'practice architectures', that enable and constrain particular practices. For example, ME careers may be enabled by the extent to which they are valued in a given setting (discursive-cultural), supported by institutional structures and employment (material-economic), and re-created through social interactions such as dedicated conferences (socio-political). Thus, practice architectures can influence how careers develop, for example by enhancing or diminishing motivation to embark on a career as a medical educator.

Using the Theory of Practice Architectures (TPA) as a conceptual lens, we investigated the emergence and subsequent development of medical education careers in a resource-constrained country, with the aim of generating findings relevant to other contexts.

\section{Methods}

We conducted a qualitative interview study to explore and describe the contextual influences on ME careers, from the perspectives of medical educators in Sri Lanka.

\section{Historical context}

In 1973, the World Health Organization (WHO) enabled the establishment of a Regional Teacher Training Centre in Medical Education for South and Southeast Asia in the Faculty of Medicine, University of Peradeniya, Sri Lanka. This support aligned with the Faculty leadership's desire for a dedicated unit, so the first Medical Education Unit was born, offering faculty development as a key focus. Since then, ME in Sri Lanka has greatly advanced, with units recognised as autonomous departments of ME (since 1996), the aforementioned postgraduate qualifications (since 2009), professional associations (since 2011), and international scientific meetings (since 2014) dedicated to $M E$.

\section{Participants}

Medical educators were purposively sampled at two career stages, 'early career' university academics still completing postgraduate qualifications in $M E$, and ME leaders who had postgraduate qualifications or leadership positions in ME. Typical of resource-constrained settings, medical educators often work alone or in small units; they do not sub-specialise in areas such as simulation or faculty development. Twenty eligible participants from all 9 medical faculties and the sole postgraduate institute in Sri Lanka were invited by email. These 20 comprised all staff appointed as educators at these institutions, and all accepted the invitation.

\section{Interviews}

Data were collected through semi-structured, in-depth interviews between 2016 and 2018 (WH, AO). Interview questions were adapted from an international research program (Hu et al. 2015; Varpio, O'Brein, $\mathrm{Hu}$, et al. 2017; Varpio, O'Brein, Durning, et al. 2017) on ME units and careers, and revised to be appropriate to the study setting. Interview topics included career entry, rewards and challenges, with questions such as 'what led you to a career in medical education?' (see Supplementary Appendix 1). Interviews of up to 60 minutes were conducted in English, audio-recorded and transcribed verbatim. Data collection was completed when preliminary analysis revealed no new findings, after 14 interviews with educators from all 10 institutions.

\section{Reflexivity and analysis}

Being researchers at different career stages, with diverse backgrounds in medicine $(\mathrm{AO}, \mathrm{WH})$ and educational sciences (RS), and working in different countries (Sri Lanka, Australia and the Netherlands), broadened and deepened our data analysis and interpretations. Two researchers had in-depth understanding of, and experience in, the Sri Lankan medical education context $(\mathrm{AO}, \mathrm{WH})$, and we collectively had an understanding of global medical education developments.

Preliminary thematic analysis was conducted (AO) and reviewed (RS) to identify emergent concepts. Themes were then refined using the conceptual lenses of TPA. Further data analysis, searching for contrary views, what TPA highlighted or did not highlight, occurred between all authors until findings were confirmed.

Ethical approval was obtained from the Faculty of Medicine - Colombo (ID EC-15-097).

\section{Results}

The 14 participants were aged between 35 and 60 years, with academic careers of at least 8 years. Career stages varied from early career lecturers (7) to ME leaders, such as 
unit directors (7). Thirteen participants were from the 9 medical faculties, one from the postgraduate institute. Six were female and 5 had professorial titles. Except for one science graduate, all were medical graduates. Six had PhDs in medical education obtained overseas, and 5 were enrolled in the postgraduate institute's ME training pathway.

Through the lenses of TPA, three themes highlighting the contextual features which influenced the emergence and subsequent development of ME careers were identified: faculty development as a career-building discourse (discursive-cultural), leadership focused on creating a workforce with expertise in medical education equal to clinical medicine specialties (material-economic), and collaborative professional networks in health professions education originating from faculty development activities (socio-political). The themes are described below with illustrative quotes.

\section{Faculty development as a career-building discourse (discursive - cultural)}

Through the discursive-cultural lens, the centrality of faculty development as a career-building discourse enabled by particular contextual factors became apparent. The WHO Regional Teacher Training Centre created an impetus for careers in $M E$, fuelling recruitment of fulltime medical educators tasked with national and regional responsibilities in faculty development. Through faculty development programmes, the educators' expertise and careers became recognised - 'people have got to know that there are full-timers doing it as a discipline' (P1, leader). Participants recalled how the unit's faculty development programmes stimulated a discourse emphasising ME expertise, and that ME was a profession in its own right. These ideas were instilled and then disseminated by those who attended.

[ME unit] used to conduct training for the academic staff on a regular basis, and my eyes opened to the fact that though I had a medical background and graduate training ... that I knew very little about the educational aspect of things. (P8, leader)

Yet, there were persistent doubts about medical educator roles: '....even today some people ask What do you do? What do you teach?'. (P1, leader). To counter doubts, medical educators and leaders continued promoting $\mathrm{ME}$ expertise through faculty development within their own institutions and with other institutions. Through increased visibility and practical assistance such as curriculum design advice, medical educators motivated young academics to start a ME career, even during times of national instability:

I was introduced to medical education when our Faculty [in a war affected area] had a workshop series and people from medical education from [Medical Education Unit in the capital] came. It was then that I first knew that there was a job such as a medical educationalist. (P3, early career)

Also stimulating a career discourse based on faculty development were global developments in quality assurance, creating further demand for trained medical educators:

The world picture has also changed, quality assurance is coming up, so it demands that people have a better training in medical education. (P4, leader)

\section{Leadership focused on creation of a medical education workforce (material - economic)}

The material-economic TPA lens revealed the critical role of leaders in stimulating ME careers by identifying promising educators and mobilising resources to pursue ME careers. ME leaders generated formal recognition for ME careers by creating a new postgraduate programme in $M E$ at the postgraduate institute:

We designed the [postgraduate training in $\mathrm{ME}$ ] programme so that people who see their careers as being in medical education could go on to do the MD [in Medical Education] (P8, leader)

ME leaders created structures such as a national professional association to mirror that of the established clinical medicine specialties. These structures fostered career recognition and visibility amongst potential trainees as well as clinical and medical school colleagues:

With the [Medical Education] College we are also now on that discipline level, they've recognised medical education as a discipline. It gives status and recognition for us. (P9, leader)

Partly driven by the increased demand for ME experts, ME leaders gradually transformed career entry from ad hoc to selective recruitment, supported by permanent career pathways:

Before I chose this as a career path, I [inquired] from my teachers at the medical faculty... They said that it is a rapidly expanding field and they foresee a good future in a professional sense. They were right. (P12, early career)

Recognition of ME expertise brought unintended challenges, such as migration of Sri Lankan medical educators to meet international expectations for quality ME. Sri Lankan leaders countered this challenge by supporting overseas professional development for early career educators, thus acknowledging the attraction of such opportunities, while fostering an obligation to return. Medical educators with overseas experience could then facilitate connections with the international scholarly community, adoption of best practices, and peer recognition:

We need to have international collaborations. For people to spend some time in those institutions, learn new ways of doing things and then come back and put it into practice. (P8, leader)

To align teaching demands with expectations to do research, ME leaders promoted research on local service needs that could be recognised for academic career advancement:

Generating evidence from your own setting is more valued than what is being generated from other contexts. (P4, leader)

\section{Collaborative professional networks in health professions education (socio - political)}

The socio-political lens indicated how ME careers were fostered by strong collaborative networks within, and between, institutions promoting scholarly exchange on teaching practice and new developments. Emerging from faculty development activities such as training programs and national conferences, these networks also made $\mathrm{ME}$ careers visible to a broad and inclusive range of participants. 
Educators in less well-resourced institutions, such as new medical schools and those in war affected areas, were explicitly encouraged through network connections to seek support from educators in more established units. This occurred through invitations to visit and conduct collaborative projects with educators in these units, and through educators from these units travelling to new medical schools to co-deliver faculty development. Thus, ME careers outside the larger centres were stimulated.

To counter the relative power and dominance of the clinical disciplines in medical programs, educators deliberately invited clinicians to co-deliver faculty development and collaborate on research. These clinicians became ME advocates:

It's well received if a clinician who understands the principles of clinical teaching and who has done it, is doing it. So we invite a clinician who is well known for good teaching to do a session. (P4, leader)

Recognising that including other health professions would increase any clinical impact from educational activities, medical educators invited nursing and allied health professionals as well:

We train nurses and all, for certificate and diploma [in medical education]. We need other professionals also, developing just doctors will not improve clinical practice. (P5, early career)

Collaboration between undergraduate and postgraduate medical educators also widened the impact of these networks. For example, faculty development of clinical trainers in the postgraduate institute was led by medical educators from undergraduate medical faculties:

When I first did my session about portfolios at the PGIM, people thought portfolios are not good enough. But gradually they realised that some aspects cannot be assessed by conventional assessments. Now portfolios are being used frequently and people get our advice and share their difficulties with us. (P13, leader)

\section{Discussion}

We applied the lenses of 'practice architectures' to investigate the emergence and subsequent development of ME careers from the perspectives of medical educators in a resource-constrained setting. Within a particular historical context, we identified the key influences on career advancement as being faculty development as a wellestablished discourse; leaders who were focused on creating a workforce with expertise in ME that would be equal to clinical medicine specialties; and cross-institutional collaborative networks for exchanging and building expertise through faculty development.

The importance of contextual influences on ME practice is well recognised, with emerging examples in faculty development (Olupeliyawa et al. 2020). As our study shows, using TPA theory can identify what these influences are and can help to explain how they have led to the current situation in particular contexts. In Sri Lanka, the three overarching themes which led to career advancement were related to faculty development, with the recognition of ME training as equivalent to training clinical medicine specialties being a significant development. In a different context, analysis informed by the three conceptual lenses of TPA could identify other influences to explain career advancement. For example in another context TPA analysis might reveal that medical education scholarship units are highly significant for ME careers, by embodying a discourse of scholarship in keeping with a strong institutional research culture, by providing a material-economic structure to supervise research and employ post-doctoral scholars, and by cultivating strategic socio-political relationships in research with clinical medicine departments.

Previous research on ME careers has focused on individuals' motivations and expectations (Hu et al. 2015; Sethi et al. 2018). Our study looked beyond individuals to the contemporary institutional arrangements that support careers in ME. In contrast, other studies have only explored how unit directors and leaders indirectly support career opportunities through leadership of Medical Education Units. Their leadership helped invoke discourses to justify Medical Education Units, cultivate relationships with institutional leadership, and increase visibility of medical education (Varpio, O'Brein, Durning, et al. 2017). Our findings show how medical education leaders can directly encourage careers by working collectively beyond institutional boundaries to create nationwide career visibility and recognised training pathways. Sri Lanka's success in ME career advancement is notable given that formal pathways are yet to gain support in other, well-resourced countries (Hu et al. 2015).

A limitation of our study is that it only explains how ME careers were established in a single resource-constrained setting. However, using a theoretical framework to guide our analysis enhances the transferability of our results. Furthermore, we will be testing the TPA approach in different, contrasting contexts, including Vietnam and the Netherlands in another study, to understand how ME careers were established and further developed in those contexts.

Our study suggests practical implications for establishing careers in $\mathrm{ME}$, whether in resource-constrained or well-resourced settings. Our results show that promoting a discourse of faculty development as a suitable basis for a career in ME can be effective. Medical educators in Sri Lanka have historically invested in faculty development, particularly in formal training programmes. Leaders extended this focus by promoting faculty development as a necessity, requiring dedicated resources and staff, and by creating the conditions to make such careers attractive, such as formal qualifications and support for further training abroad. The impact of faculty development activities can be strengthened by inviting other health professions and postgraduate clinical trainers as participants, and then as co-facilitators in faculty development.

In conclusion, our findings highlight that faculty development can foster a powerful discourse for promoting academic careers in $\mathrm{ME}$, that ME leaders can play a critical role by establishing formal training programmes in $M E$, and that collaborative professional networks can improve visibility of careers in ME when participants share expertise and resources between institutions and health professions, and across the continuum of undergraduate to postgraduate training. TPA can also be used to better understand how cultural, material-economic and socio-political factors can enhance or hinder career development in different contexts, whether resource-limited or well-resourced. 


\section{Disclosure statement}

The authors report no conflicts of interest. The authors alone are responsible for the content and writing of the article.

\section{Glossary}

Context: The conditions (e.g. physical environment, roles and interpersonal relationships, culture) in which medical educators work and careers are established. Context may be understood at an institutional, national or regional level.

Theory of Practice Architectures: A theory on how professional practices, defined by social and ethical understanding of that profession, develop and are shaped by institutional arrangements in particular contexts. These arrangements are discursive (the way people speak and communicate), materialeconomic (the formal rules, or physical resources) and sociopolitical (the social relationships, including power hierarchies).

\section{Notes on contributors}

Asela M. Olupeliyawa, MBBS, PhD, is a Professor in the Department of Medical Education and WHO Collaborating Centre for Medical Education, Faculty of Medicine, University of Colombo, Colombo, Sri Lanka.

Wendy C. Y. Hu, MBBS, PhD, is a Chair, and Professor of Medical Education, Associate Dean of Learning and Innovation, School of Medicine, Western Sydney University, Sydney, Australia.

Renée E. Stalmeijer, PhD, is an Assistant Professor in the Department of Educational Development and Research, School of Health Professions Education, Faculty of Health, Medicine and Life Sciences, Maastricht University, Maastricht, the Netherlands.

\section{ORCID}

Asela M. Olupeliyawa (D) http://orcid.org/0000-0002-7665-6458
Wendy C. Y. Hu iD http://orcid.org/0000-0002-1711-3808

Renée E. Stalmeijer (D) http://orcid.org/0000-0001-8690-5326

\section{References}

Hu WCY, Thistlethwaite JE, Weller J, Gallego G, Monteith J, McColl GJ. 2015. 'It was serendipity': A qualitative study of academic careers in medical education. Med Educ. 49 (11):1124-1170.

Karunathilake I, Samasekera D, Dias R, Olupeliyawa A. 2006. Medical education reforms in Sri Lanka. Asia Pacific Biotech. 10(15):809-811.

Kemmis S, Heikkinen HLT, Fransson G, Aspfors J, Edwards-Groves C. 2014. Mentoring of new teachers as a contested practice: supervision, support and collaborative self-development. Teach Educ. 43: 154-164.

Kiguli-Malwadde E, Talib JM, Wohltjen H, Connor SC, Gandari J, Banda SS, Maggio LA, van Schalkwyk SC. 2015. Medical education departments: a study of four medical schools in Sub-Saharan Africa. BMC Med Educ. 15:109.

Mahon K, Kemmis S, Francisco S, Lloyd A. 2017. In practice theory and the theory of practice architectures. In: Mahon $\mathrm{K}$, Francisco $\mathrm{S}$, Kemmis S, editors. Exploring education and professional practice: through the lens of practice architectures. Singapore: Springer; $p$. $1-30$.

Olupeliyawa AM, Venkateswaran S, Wai N, Mendis K, Flynn E, Hu W. 2020. Transferability of faculty development resources. Clin Teach. 17(1):86-91.

Postgraduate Institute of Medicine (PGIM) - Doctor of Medicine (MD) and Board Certification in Medical Education. 2016. Colombo: Official website of the Postgraduate Institute of Medicine. [accessed 2021 Jan 10]. https://pgim.cmb.ac.lk/index.php/md-medicaleducation.

Sethi A, Schofield S, McAleer S, Ajjawi R. 2018. The influence of postgraduate qualifications on educational identity formation of healthcare professionals. Adv Health Sci Educ. 23:567-585.

Varpio L, O'Brien B, Hu W, ten Cate O, Durning SJ, van der Vleuten C, Gruppen L, Irby D, Humphrey-Murto S, Hamstra SJ. 2017. Exploring the institutional logics of health professions education scholarship units. Med Educ. 51(7):755-767.

Varpio L, O'Brien B, Durning S, van der Vleuten C, Gruppen L, ten Cate O, Humphrey-Murto S, Irby DM, Hamstra SJ, Hu W. 2017. Health professions education scholarship unit leaders as institutional entrepreneurs. Acad Med. 92(8):1189-1195. 